\title{
Avaliação de Algumas Características da Silagem de Gramínea Estrela Roxa (Cynodon nlemfuensis Vanderyst) ${ }^{1}$
}

\section{Antônio Ricardo Evangelista², Josiane Aparecida de Lima ${ }^{3}$, Thiago Fernandes Bernardes ${ }^{4}$}

RESUMO - O experimento foi realizado para avaliar características da silagem da gramínea estrela roxa (Cynodon nlemfuensis Vanderyst) submetida à adição de aditivo seco e diferentes tempos de emurchecimento. A gramínea foi colhida com aproximadamente 45 dias de rebrota e permaneceu ensilada por 35 dias. Os tratamentos foram: 1 - ensilagem imediatamente após o corte; 2 - ensilagem imediatamente após o corte com adição de 4\% de polpa cítrica; 3 - ensilagem após emurchecimento por uma hora; 4 - ensilagem após emurchecimento por uma hora com adição de 4\% de polpa cítrica; 5 - ensilagem após emurchecimento por duas horas; 6 - ensilagem após emurchecimento por duas horas com adição de 4\% de polpa cítrica; 7 - ensilagem após emurchecimento por três horas; e 8 ensilagem após emurchecimento por três horas com adição de $4 \%$ de polpa cítrica. A polpa cítrica foi adicionada à gramínea com base na matéria verde. Os parâmetros analisados ( $\mathrm{pH}, \mathrm{MS}, \mathrm{PB}, \mathrm{FDN}$ e FDA) permitem concluir que a gramínea estrela roxa ensilada imediatamente após o corte ou submetida ao emurchecimento até três horas, com ou sem adição de polpa cítrica, pode ser satisfatoriamente armazenada na forma de silagem.

Palavras-chave: matéria seca, $\mathrm{pH}$, polpa cítrica, emurchecimento, proteína bruta

\section{Evaluation of Some Characteristics of Star Grass (Cynodon nlemfuensis Vanderyst) Silage}

ABSTRACT - This experiment was conducted to evaluate the characteristics of the silage of the star grass (Cynodon nlemfuensis Vanderyst) with or without addition of citric pulp and submitted to different wilting time. The grass was harvested after 45 days of sprouting and stored for 35 days. The treatments were: 1 - ensilage immediately after the cut, 2 - ensilage immediately after the cut with the addition of $4 \%$ citric pulp, 3 - ensilage after wilting for one hour, 4 - ensilage after wilting for one hour with the addition of $4 \%$ citric pulp, 5 - ensilage after wilting for two hours, 6 - ensilage after wilting for two hours with the addition of $4 \%$ citric pulp, 7 - ensilage after wilting for three hours, and 8 . ensilage after wilting for three hours with the addition of $4 \%$ citric pulp. The citric pulp was added to the fresh green forage. The analyzed characteristics ( $\mathrm{pH}, \mathrm{DM}, \mathrm{CP}, \mathrm{NDF}$ and ADF) allowed to conclude that the star grass, stored immediately after the cut or submitted to a wilting period up to three hours, with or without the addition of citric pulp, could be preserved satisfactorily in the form of fodder in a silo.

Key Words: citric pulp, crude protein, dry matter, $\mathrm{pH}$, wilting

\section{Introdução}

Na região sul de Minas Gerais, principalmente em fazendas de produção de leite, a técnica de conservação de forragens na forma de feno vem sendo cada vez mais utilizada pelos pecuaristas e, entre as espécies forrageiras mais empregadas para esta prática, destacam as gramíneas do gênero Cynodon, em função de serem forrageiras que se adaptam ao clima tropical e subtropical, com alto potencial produtivo, elevado valor nutritivo e excelente aceitabilidade pelos animais.

A época propícia para a produção de feno de boa qualidade é aquela que vai de outubro a março (época de chuvas), coincidindo, portanto, com o máximo crescimento vegetativo da forrageira, bem como com o seu melhor valor nutritivo. Entretanto, o processo tradicional de obtenção de feno consiste no corte e na exposição da forrageira ao sol por um período de dois ou mais dias consecutivos, submetendo-se a forragem a viragens sucessivas para uniformizar e acelerar a desidratação. Considerando que existe a necessidade de se contar com dias abertos e ensolarados para a secagem das plantas, o processo de fenação apresenta um sério entrave, uma vez que o momento ideal para o corte das forrageiras coincide com a época de chuvas.

Nesse contexto, sugere-se que, na iminência de

\footnotetext{
${ }^{1}$ Projeto parcialmente financiado pelo CNPq.

2 Professor Titular do Departamento de Zootecnia da UFLA. Bolsista do CNPq. e-mail: aricardo@ufla.br

${ }^{3}$ D.S. Forragicultura e Pastagens. Bolsista Recém-Doutor - CNPq. e-mail: jlima @ ufla.br

${ }^{4}$ Estudante de Graduação do Curso de Agronomia da UFLA. Bolsista de Iniciação Científica - CNPq
} 
ocorrência de chuvas consecutivas, gramíneas do gênero Cynodon sejam armazenadas na forma de silagem. Acredita-se que, com a adoção dessa estratégia de manejo do campo de feno, evita-se a presença de forragem envelhecida e aumenta a quantidade de alimento volumoso de boa qualidade para ser fornecido ao rebanho na época seca. Caso contrário, a forragem passada do ponto presente no campo de feno, tem que ser cortada e retirada da área, sendo jogada fora na maioria das vezes.

Levando-se em consideração estudos realizados em outros países, conforme McCORMICK et al. (1957), CLIFTON et al. (1963), MILLER et al. (1963, 1966), KING et al. (1964), KUNKLE et al. (1988), UMAÑA et al. (1991), BERTHE (1992) e STAPLES et al. (1993), entre outros, gramíneas do gênero Cynodon podem ser eficientemente conservadas na forma de silagem.

VILELA e ALVIM (1998) compartilham da mesma opinião, mencionando que, em situações em que o preparo de feno é difícil, a ensilagem destas gramíneas pode ser uma alternativa e CORSI e MARTHA JR. (1998) acreditam que, a partir da conservação do Cynodon na forma de silagem, quando o processo é executado de forma correta, podem ser obtidos produtos que se equiparam à qualidade dos obtidos por métodos mais tradicionais, como a utilização de silagem de milho.

Uma característica do gênero Cynodon que deve ser considerada é a rapidez na perda de umidade, quando submetido ao emurchecimento. Nesse sentido, KUNKLE et al. (1988) observaram que uma a duas horas de emurchecimento do Cynodon com idade entre cinco e seis semanas de rebrota foram suficientes para elevar o teor inicial de matéria seca de $25 \%$ para 35 a $40 \%$ e emurchecimento por duas horas e meia a quatro horas elevou o teor inicial de matéria seca de $25 \%$ para 45 a $50 \%$.

Considerando que é comum, na época ideal de corte das forrageiras, um dia ou apenas algumas horas de céu aberto seguidos de dias chuvosos consecutivos, esta característica de rápida perda de umidade se traduz em substancial vantagem.

Por outro lado, um dos problemas associados à ensilagem de gramíneas do gênero Cynodon é a sua baixa concentração em carboidratos solúveis. UMAÑA et al. (1991) confirmam esse fato, ao observarem nessa espécie forrageira (Bermudagrass) somente $2,85 \%$ de carboidratos solúveis na matéria seca. Segundo LANINGAN e CATCHPOOLE (1962), o conteúdo de carboidratos solúveis na matéria seca de uma forrageira, para produção de boa silagem, deve situar-se em torno de $10 \%$.

Considerando o exposto e a escassez de informações sobre a ensilagem de gramíneas do gênero Cynodon em condições brasileiras, desenvolveu-se o presente estudo com o intuito de avaliar algumas características da silagem do capim-estrela roxa.

\section{Material e Métodos}

O presente trabalho foi conduzido em área pertencente ao Departamento de Zootecnia da Universidade Federal de Lavras-MG. Segundo CASTRO NETO et al. (1980), Lavras está situada a $21^{0} 14^{\prime}$ de latitude sul e $45^{\circ} 00^{\prime}$ 'de longitude oeste de Greenwich, com altitude média de 910 metros. O clima, segundo classificação de Koppen, é do tipo Cwb (OMETTO, 1981), caracterizando-se por duas estações bem definidas - 'seca' de abril a setembro e 'chuvosa' de outubro a março. A precipitação média anual é de $1493 \mathrm{~mm}$ e as temperaturas médias de máxima e mínima são de 26,0 e $14,6^{\circ} \mathrm{C}$, respectivamente.

Durante a colheita, o emurchecimento e a ensilagem da forragem, os dados meteorológicos foram: precipitação pluviométrica, $0 \mathrm{~mm}$; radiação solar, 10 horas e 18 minutos; umidade relativa do ar, $71 \%$; temperatura média, $23,6 \%$, máxima, $30,5 \%$ e mínima, 18,9\%; e velocidade média do vento, 2,0 metros/segundo.

O capim-estrela roxa foi colhido em 14/04/98 após, aproximadamente, 45 dias de rebrota, sendo o corte realizado com segadeira mecânica. Quando pertinente, a gramínea permaneceu no campo espalhada uniformemente, sendo submetida a diferentes tempos de emurchecimento, originando os seguintes tratamentos:

1 - ensilagem imediatamente após o corte;

2 - ensilagem imediatamente após o corte com adição de $4 \%$ de polpa cítrica;

3 - ensilagem após emurchecimento por uma hora;

4 - ensilagem após emurchecimento por uma hora com adição de $4 \%$ de polpa cítrica;

5 - ensilagem após emurchecimento em por duas horas;

6 - ensilagem após emurchecimento por duas horas com adição de $4 \%$ de polpa cítrica;

7 - ensilagem após emurchecimento por três horas; e

8 - ensilagem após emurchecimento por três horas com adição de $4 \%$ de polpa cítrica.

A composição química da polpa cítrica foi a 
seguinte: matéria seca (88\%), proteína bruta $(6 \%)$, fibra em detergente neutro (25\%), fibra em detergente ácido (24\%), matéria mineral (6\%), cálcio (1,59\%) e fósforo $(0,08 \%)$. A polpa cítrica, na forma peletizada, foi misturada à forragem manualmente, na base da matéria natural, no momento da ensilagem.

O delineamento experimental foi completamente casualizado, com três repetições. Os dados foram analisados estatisticamente pela análise de variância, sendo as médias comparadas pelo teste Tukey.

A gramínea foi picada e recolhida por uma máquina JF-90Z equipada com KIT R-90 e enleirada com a utilização de um ancinho mecânico. Utilizaram-se três silos de superfície, para cada tratamento, com dimensões de 2,5 x 2,5 m e altura de $0,7 \mathrm{~m}$. A compactação realizada por trator foi feita à medida que se colocava o material no silo. Após enchimento e compactação, vedou-se o silo com lona plástica, sobre a qual foi colocada uma camada de terra para melhor proteção, onde o material permaneceu por 35 dias.

Após a abertura, em cada silo, tomaram-se amostras das silagens em diferentes pontos, que foram misturadas retirando-se uma amostra de aproximadamente $500 \mathrm{~g}$, sendo essas imediatamente conduzidas ao laboratório de Nutrição Animal do DZO-UFLA.

No laboratório, as amostras foram pré-secadas em estufa a $60^{\circ} \mathrm{C}$ por 72 horas, moídas e acondicionadas para posteriores análises. Os teores de matéria seca, proteína bruta, minerais, cálcio e fósforo foram determinados conforme a técnica da AOAC (1975). Os teores de fibra em detergente neutro e fibra em detergente ácido foram determinados segundo as técnicas descritas por GOERING e VAN SOEST (1970). O pH foi medido em potenciômetro a partir de um extrato de silagem obtido do filtrado de $50 \mathrm{~g}$ de silagem, após ter sido triturada em liqüidificador com $200 \mathrm{~mL}$ de água destilada. A energia bruta foi determinada em bomba calorimétrica 1241 Parr, conforme SILVA (1990).

\section{Resultados e Discussão}

\section{Matéria seca, pH e proteína bruta}

Os teores de matéria seca (MS), valores de $\mathrm{pH}$ e teores de proteína bruta (PB) das silagens podem ser observados na Tabela 1 .

Constatou-se aumento nos teores de MS das silagens, em função dos tempos de emurchecimento e da adição de polpa cítrica. Para silagens que não receberam polpa cítrica, o emurchecimento da forragem por três horas elevou o teor de MS em 15,5 unidades percentuais e, para as silagens acrescidas de polpa cítrica, em 14,1 unidades percentuais, em relação às silagens que não foram submetidas ao emurchecimento.

A rapidez na perda de umidade de algumas espécies do gênero Cynodon durante o emurchecimento também foi observada por KUNKLE et al. (1988). Por sua vez, UMAÑA et al. (1991), submetendo o Cynodon (Bermudagrass) por apenas uma hora de emurchecimento, obtiveram aumento no teor de MS da ordem de 12 unidades percentuais, enquanto STAPLES et al. (1993), com três horas de exposição da forragem ao sol, elevaram o teor de MS da silagem em 10 unidades percentuais.

Considerando que é comum na época ideal de corte das forrageiras um dia ou apenas algumas horas de sol aberto seguido de dias chuvosos consecutivos, esta característica de rápida perda de umidade se traduz em substancial vantagem do capim-estrela roxa em relação à outras espécies forrageiras. Como

Tabela 1 - Efeito do tempo de emurchecimento e da adição de polpa cítrica no teor de matéria seca (MS), valor de $\mathrm{pH}$ e teor de proteína bruta (PB) da silagem de estrela roxa

Table 1 - Effect of the wilting period and addition of citric pulp on the dry matter content (DM), $\mathrm{pH}$ value and crude protein content $(C P)$ in the star grass ensilage

\begin{tabular}{|c|c|c|c|c|c|c|}
\hline \multirow{2}{*}{$\begin{array}{l}\text { Tempo de emurchecimento } \\
\text { (horas) } \\
\text { Wilting period (hours) }\end{array}$} & \multicolumn{3}{|c|}{$\begin{array}{l}\text { Sem polpa cítrica } \\
\text { Without citric pulp }\end{array}$} & \multicolumn{3}{|c|}{$\begin{array}{l}\text { Com polpa cítrica } \\
\text { With citric pulp }\end{array}$} \\
\hline & $\begin{array}{c}\mathrm{MS}(\%) \\
D M \\
\end{array}$ & $\mathrm{pH}$ & $\begin{array}{l}\mathrm{PB}(\% \mathrm{MS}) \\
C P(\% D M)\end{array}$ & $\begin{array}{c}\mathrm{MS}(\%) \\
D M \\
\end{array}$ & $\mathrm{pH}$ & $\begin{array}{l}\mathrm{PB}(\% \mathrm{MS}) \\
C P(\% D M)\end{array}$ \\
\hline 0 & $26,3^{\mathrm{Cb}}$ & $4,0^{\mathrm{Ba}}$ & $13,8^{\mathrm{Aa}}$ & $29,3^{\mathrm{Ca}}$ & $3,9^{\mathrm{Ca}}$ & $12,9^{\mathrm{Ab}}$ \\
\hline 1 & $34,8^{\mathrm{Bb}}$ & $4,1^{\mathrm{Ba}}$ & $14,1^{\mathrm{Aa}}$ & $35,4^{\mathrm{Ba}}$ & $4,2^{\mathrm{Ba}}$ & $13,0^{\mathrm{Ab}}$ \\
\hline 2 & $33,4^{\mathrm{Bb}}$ & $4,3^{\mathrm{ABa}}$ & $13,6^{\mathrm{Aa}}$ & $37,2^{\mathrm{Ba}}$ & $4,3^{\mathrm{ABa}}$ & $13,1^{\mathrm{Ab}}$ \\
\hline 3 & $41,8^{\mathrm{Ab}}$ & $4,5^{\mathrm{Aa}}$ & $12,6^{\mathrm{Aa}}$ & $43,4^{\mathrm{Aa}}$ & $4,6^{\mathrm{Aa}}$ & $12,3^{\mathrm{Ab}}$ \\
\hline
\end{tabular}

Médias seguidas de mesma letra maiúscula na coluna e minúscula na linha, para cada parâmetro, não diferem pelo teste Tukey $(\mathrm{P}<0,05)$.

Means for each parameter, followed by the same uppercase letter in the column and lowercase letter in the row, do not differ by Tukey test $(P<.05)$. 
exemplo, citam-se LOPEZ e MÜHLBACH (1991), que, trabalhando com aveia branca, colhida no início do florescimento, necessitaram de 45 horas de exposição da forragem ao sol para elevar o teor de MS das silagens de 18,8 para $32,4 \%$, e BERTO e MÜHLBACH (1997), os quais submeteram a aveia preta, colhida aos 66 dias após o plantio, a 26 horas de exposição ao sol, para elevar o teor de MS da silagem de 15,3 para $31,2 \%$.

Sendo o teor mínimo de $30 \%$ de MS adequado para ensilagem (SILVEIRA, 1975), apenas as silagens que não foram submetidas ao emurchecimento, com ou sem adição de polpa cítrica, apresentaram valores abaixo do mínimo preconizado. Entretanto, vale ressaltar que a silagem acrescida de polpa e não submetida ao emurchecimento apresentou teor de MS (29,3\%) muito próximo ao valor mínimo de $30 \%$.

Quanto às silagens que apresentaram teor de MS acima de 35\%, WOOLFORD (1981) menciona que alto teor de MS reduz a atividade bacteriana na silagem e a atividade clostridiana na silagem com teor de MS entre 35 e $40 \%$ é substancialmente reduzida ou inexistente, permitindo, assim, que as bactérias ácido láticas produzam ácido lático suficiente para estabilizar a silagem.

Quando se analisa o efeito da adição de polpa cítrica, observa-se que os maiores teores de MS foram constatados nas silagens que receberam esse aditivo, em conseqüência do elevado teor de MS apresentado pela polpa cítrica $(88 \%)$.

Os valores de $\mathrm{pH}$ das silagens indicam efeito significativo somente entre os tempos de emurchecimento, sendo os maiores valores observados quando a forragem foi submetida a três horas de emurchecimento. Possivelmente, esse fato ocorreu em função do maior teor de MS dessas silagens, em relação às demais, o que, segundo McDONALD (1981), leva à menor produção de ácidos, em função do aumento da pressão osmótica.

BREIREM e ULVESLI (1960) mencionaram que o limite superior de $\mathrm{pH}$ para silagens de qualidade satisfatória é igual a 4,2. Dessa forma, as silagens que foram submetidas ao emurchecimento por duas e três horas apresentaram valores superiores ao limite máximo. Entretanto, valores de $\mathrm{pH}$ superiores ao limite máximo preconizado pelos autores supracitados foram observados por vários autores (MILLER et al., 1963, 1967; UMAÑA et al., 1991; e STAPLES et al., 1993) em silagens de gramíneas do gênero Cynodon, cujos valores variaram entre 4,5 e 5,3 , dependendo do estádio de desenvolvimento da planta ou do uso ou não do emurchecimento.
Em silagens convencionalmente conservadas, o pH elevado é indicativo de grande produção de ácidos mais fracos, como o butírico e o acético, que são oriundos de fermentações indesejáveis (VAN SOEST, 1994). Entretanto, o pH isoladamente não pode ser considerado como critério seguro para avaliação da fermentação, pois seu efeito inibitório sobre as bactérias depende da velocidade do abaixamento da concentração iônica e do grau de umidade do meio (WOOLFORD, 1984).

Quanto à proteína bruta, houve efeito somente para a adição de polpa cítrica. Os maiores valores foram observados nas silagens sem polpa (teor médio $=13,5 \%)$, em relação às silagens que foram acrescidas de polpa cítrica (teor médio $=12,8 \%$ ).

Embora tenha sido constatada diferença, a redução no teor protéico médio das silagens que receberam polpa foi de apenas 0,7 unidades percentuais, ocorrido em função do efeito de diluição proporcionado pela adição da polpa cítrica.

Fibra em detergente neutro, fibra em detergente ácido e energia bruta

Os resultados referentes ao teor de fibra em detergente neutro (FDN), fibra em detergente ácido (FDA) e valores de energia bruta (EB) são apresentados na Tabela 2.

Para a FDN constatou-se diferença entre os tempos de emurchecimento somente para as silagens que não foram acrescidas de polpa cítrica; entretanto, a adição da polpa foi significativa somente nos tempos zero e uma hora de emurchecimento.

Com relação ao tempo de emurchecimento, para as silagens sem polpa cítrica, constatou-se redução de 4,3 unidades percentuais no teor de FDN, quando se compara o valor observado na silagem não submetida ao emurchecimento $(82,7 \%)$, em relação à silagem submetida a três horas de emurchecimento $(78,4 \%)$. Entretanto, esperava-se o contrário, uma vez que, quanto maior o tempo de exposição da forragem ao sol, maiores são as perdas de compostos solúveis, elevando, assim, os valores de FDN.

No tocante à FDA, houve efeito da polpa cítrica, sendo de maior amplitude as diferenças observadas nas silagens que receberam polpa nos tempos zero, uma e duas horas de emurchecimento, em relação às silagens não acrescidas de polpa cítrica.

Quanto à EB, observou-se diferença somente para a adição de polpa cítrica; entretanto, parece não ter ocorrido efeito consistente que possa ser atribuído à presença da polpa nas silagens submetidas aos diferentes tempos de emurchecimento. 
Rev. bras. zootec.

Tabela 2 - Efeito do tempo de emurchecimento e da adição de polpa cítrica no teor de fibra em detergente neutro (FDN), fibra em detergente ácido (FDA) e valores de energia bruta (EB) da silagem de estrela roxa

Table 2 - Effect of the wilting period and addition of citric pulp on the fiber content in neutral detergent fiber (NDF), acid detergent fiber (ADF) and values of gross energy (GE) in the star grass ensilage

\begin{tabular}{|c|c|c|c|c|c|c|}
\hline \multirow[t]{2}{*}{$\begin{array}{l}\text { Tempo de emurchecimer } \\
\text { (horas) }\end{array}$} & \multicolumn{3}{|c|}{$\begin{array}{l}\text { Sem polpa cítrica } \\
\text { Without citric pulp }\end{array}$} & \multicolumn{3}{|c|}{$\begin{array}{l}\text { Com polpa cítrica } \\
\text { With citric pulp }\end{array}$} \\
\hline & $\begin{array}{l}\mathrm{FDN}(\%) \\
\quad N D F\end{array}$ & $\begin{array}{c}\mathrm{FDA}(\%) \\
\quad A D F\end{array}$ & $\begin{array}{l}\mathrm{EB}(\mathrm{kcal} / \mathrm{kg}) \\
G E(k c a l / \mathrm{kg})\end{array}$ & $\begin{array}{l}\mathrm{FDN}(\%) \\
\quad N D F\end{array}$ & $\begin{array}{l}\mathrm{FDA}(\%) \\
\quad A D F\end{array}$ & $\begin{array}{l}\mathrm{EB}(\mathrm{kcal} / \mathrm{kg}) \\
G E(k c a l / k g)\end{array}$ \\
\hline 0 & $82,7^{\mathrm{Aa}}$ & $38,4^{\mathrm{Ab}}$ & $4382^{\mathrm{Ab}}$ & $77,7^{\mathrm{Ab}}$ & $39,9^{\mathrm{Aa}}$ & $4418^{\mathrm{Aa}}$ \\
\hline 1 & $80,0^{\mathrm{ABa}}$ & $40,6^{\mathrm{Ab}}$ & $4441^{\mathrm{Aa}}$ & $78,1^{\mathrm{Ab}}$ & $42,1^{\mathrm{Aa}}$ & $4432^{\mathrm{Ab}}$ \\
\hline 2 & $80,8^{\mathrm{ABa}}$ & $40,5^{\mathrm{Ab}}$ & $4414^{\mathrm{Aa}}$ & $80,4^{\mathrm{Aa}}$ & $42,0^{\mathrm{Aa}}$ & $4408^{\mathrm{Aa}}$ \\
\hline 3 & $78,4^{\mathrm{Ba}}$ & $39,8^{\mathrm{Ab}}$ & $4408^{\mathrm{Aa}}$ & $77,1^{\mathrm{Aa}}$ & $40,2^{\mathrm{Aa}}$ & $4330^{\mathrm{Ab}}$ \\
\hline
\end{tabular}

Médias seguidas de mesma letra maiúscula na coluna e minúscula na linha, para cada parâmetro, não diferem pelo teste Tukey $(\mathrm{P}<0,05)$.

Means for each parameter, followed by the same capital letter in the column and small letter in the row, do not differ by Tukey test (P<.05).

\section{Minerais, Cálcio e Fósforo}

Os valores referentes aos teores de minerais $(\mathrm{M})$, cálcio $(\mathrm{Ca})$ e fósforo $(\mathrm{P})$ podem ser observados na Tabela 3.

Os teores de minerais foram diferentes somente entre os tempos de secagem para as silagens que não foram acrescidas de polpa cítrica. Entretanto, não foram observadas diferenças substanciais, sendo o maior valor, $3,1 \%$, observado na silagem submetida a três horas de emurchecimento, e o menor valor, $2,3 \%$, na silagem não submetida ao emurchecimento. Portanto, a maior diferença observada entre os tempos de emurchecimento foi de apenas 0,8 unidades percentuais.

Quanto aos teores de Ca e P, houve diferença entre os tempos de emurchecimento somente para as silagens sem polpa cítrica, sendo a diferença entre o maior e o menor valor de 0,03 unidades percentuais, para ambos.

Tabela 3 - Efeito do tempo de emurchecimento e da adição de polpa cítrica nos teores de minerais (M), cálcio $(\mathrm{Ca})$ e fósforo $(\mathrm{P})$ da silagem de estrela roxa

Table 3 - Effect of the wilting period and addition of citric pulp on the mineral content (M), calcium (Ca) and phosphorus $(P)$ in the star grass ensilage

\begin{tabular}{|c|c|c|c|c|c|c|}
\hline \multirow[t]{2}{*}{$\begin{array}{l}\text { Tempo de emurchecime } \\
\text { Pre-drying period (hours) }\end{array}$} & \multicolumn{3}{|c|}{$\begin{array}{l}\text { Sem polpa cítrica } \\
\text { Without citric pulp }\end{array}$} & \multicolumn{3}{|c|}{$\begin{array}{l}\text { Com polpa cítrica } \\
\text { With citric pulp }\end{array}$} \\
\hline & $\mathrm{M}(\%)$ & $\mathrm{Ca}(\%)$ & $\mathrm{P}(\%)$ & $\mathrm{M}(\%)$ & $\mathrm{Ca}(\%)$ & $\mathrm{P}(\%)$ \\
\hline 0 & $2,3^{\mathrm{Ca}}$ & $0,11^{\mathrm{Bb}}$ & $0,08^{\mathrm{Ba}}$ & $2,7^{\mathrm{Aa}}$ & $0,14^{\mathrm{Aa}}$ & $0,10^{\mathrm{Aa}}$ \\
\hline 1 & $2,6^{\mathrm{BCa}}$ & $0,13^{\mathrm{Bb}}$ & $0,10^{\mathrm{ABa}}$ & $2,6^{\mathrm{Aa}}$ & $0,14^{\mathrm{Aa}}$ & $0,10^{\mathrm{Aa}}$ \\
\hline 2 & $2,7^{\mathrm{Ba}}$ & $0,14^{\mathrm{ABa}}$ & $0,11^{\mathrm{Aa}}$ & $2,7^{\mathrm{Aa}}$ & $0,14^{\mathrm{Aa}}$ & $0,10^{\mathrm{Aa}}$ \\
\hline 3 & $3,1^{\mathrm{Aa}}$ & $0,14^{\mathrm{Aa}}$ & $0,11^{\mathrm{Aa}}$ & $2,6^{\mathrm{Aa}}$ & $0,14^{\mathrm{Aa}}$ & $0,10^{\mathrm{A}}$ \\
\hline
\end{tabular}

Médias seguidas de mesma letra maiúscula na coluna e minúscula na linha, para cada parâmetro, não diferem pelo teste Tukey $(\mathrm{P}<0,05)$.

Means for each parameter, followed by the same capital letter in the column and small letter in the row, do not differ by Tukey test $(P<.05)$. 


\section{Conclusões}

A gramínea estrela roxa pode ser satisfatoriamente armazenada na forma de silagem, quando submetida ao emurchecimento ou à adição de polpa cítrica, constituindo-se em mais uma alternativa de manejo do campo de feno.

\section{Referências Bibliográficas}

AGRICULTURAL RESEARCH COUNCIL - ARC. 1980. The nutrient requirements of ruminants livestock. England: Commonwealth Agricultural Bureaux. 351p.

ASSOCIATION OF OFFICIAL AGRICULTURAL CHEMISTS - AOAC. 1975. Official methods of analyses of the association of official analytical chemists. 11.ed. Washington, D.C. $1015 \mathrm{p}$.

BERTHE, A. 1992. Effect of harvesting systems and wilting in Bermudagrass nutrient recovery and nutrient utilization by beefcattle. Florida: Gainesville. 235p. Dissertação. University of Florida.

BERTO, J.L., MÜHLBACH, P.R.F. 1997. Silagem de aveia preta no estádio vegetativo, submetida à ação de inoculantes e ao efeito do emurchecimento. R. Bras. Zootec., 26(4):651-658.

BREIREM, K., ULSVELI, O.1960. Ensiling methods. Herb. Abstr., 30(1):1-8.

CASTRO NETO, P., SEDYIMA, G.C., VILELA, E.A. 1980. Probabilidade de ocorrência de períodos secos em Lavras, Minas Gerais. Ciência e Prática, 4(1):46-55.

CLIFTON, C.M., MILLER, W.J., CAMERON, N.W. 1963. Coastal Bermudagrass hay and silage at two stages of maturity, feed with two concentrate levels to lactating cows. J. Dairy Sci., 46:959-964.

CORSI, M., MARTHA JR., B. Manejo de pastagens para produção de carne e leite. In: SIMPÓSIO SOBRE MANEJO DE PASTAGEM, 15, 1998, Piracicaba. Anais... Piracicaba: FEALQ, 1998, p.55-84.

GOERING, H.K., VAN SOEST, P.J. 1970. Forage fiber analysis: apparatus, reagents, procedures and some applications. Washington, USDA, ARS (Agriculture Handbook, 379).

KING, W.A., BRANNON, C.C., WEBB, H.J. 1964. Coastal Bermudagrass silage for milking cows. South Carolina Agr. Exp. Sta. (Bull. 516).

KUNKLE, W.E., BATES, D.B., CHAMBLISS, C.G. et al. Alternative forage storage-bale silage. In: ATHENS PROC. DAIRY HERD MANAGEMENT CONFERENCE, Georgia, 1988. Proceedings... University of Georgia, 1988. p.31-41.

LANINGAN, G.W., CATCHPOOLE, V.R. 1962. Studies on ensilage. II. Plant maturity effects in the ensilage of ryegrass and clover under laboratory conditions. Austr. J. Agric. Reser., 13(5):853-863.

LOPEZ, S.E., MÜHLBACH, P.R.F. 1991. Efeito de diferentes tratamentos na composição químico-bromatológica da aveia branca (Avena sativa L.) conservada nas formas de silagem ou feno. R. Soc. Bras. Zootec., 20(4):333-338.
McCORMICK, W.C., HALE, O.M., SOUTHWELL, B.L. 1957. The comparative value of coastal bermuda grass silage and hay forfattening steers. Georgia Agr. Espt. Sta. (Circ. NS 10).

McDONALD, P. 1981. The biochemistry of silage. New York: John Wiley. 226p.

McDONALD, P., WATSON, D., WHITTENBURY, S.J. 1966. The principles of ensilage. Edinburgh School of Agriculture: Miscelloneous. 357p.

MERTENS, D.R. 1994. Regulation of forage intake. In: FAHEY JR., G.C. (Ed.) Forage quality, evaluation, and utilization. Madison: American Society of Agronomy, Crop Science Society of America, Soil Science Society of America. p.450-493.

MILlER, W.J., CLIFTON, C.M., CAMERON, N.W. 1963. Ensiling characteristics of Coastal Bermudagrass harvested at the prehead and full-head stages of growth. J. Dairy Sci., 46:45-53.

MILLER, W.J., CLIFTON, C.M., FOWLER, P.R. et al. 1967. Comparison of low moisture and unwilted Coastal Bermudagrass silages for lactating dairy cows. J. Anim. Sci., 50(8):1262-1272.

MILLER, W.J., CLIFTON, C.M., FOWLER, P.R. et al. 1966. Ensiling characteristics of tift sudan grass and coastal bermudagrass. J. Dairy Sci., 49(5):477-485.

NATIONAL RESEARCH COUNCIL - NRC. 1989. Nutrient requirements of dairy cattle. 6 .ed. Washington, D.C. $158 \mathrm{p}$.

OMETTO, J.C. 1981. Bioclimatologia vegetal. São Paulo: Ceres. $425 \mathrm{p}$.

SILVA, D.J. 1990. Análise de alimentos: métodos químicos e biológicos. Viçosa, MG: UFV. 166p.

SILVEIRA, A.C. Técnicas para produção de silagem. In: SIMPÓSIO SOBRE MANEJO DA PASTAGEM, 2, Piracicaba, 1975. Anais... Piracicaba: Escola Superior de Agricultura 'Luiz de Queiroz', 1975, p.156-180.

STAPLES, C., RUIZ, T., BERNAL, E. 1993. Feeding Bermudagrass silage to lactating dairy cows. In: INTERNATIONAL CONFERENCE ON LIVESTOCK IN THE TROPICS, 1993, Gainesville, Florida. Proceedings... Gainesville, Florida:University of Florida, Institute of Food and Agricultural Science. p.118-128.

UMAÑA, R., STAPLES, C.R., BATES, D.B. et al. 1991. Effects of a microbial inoculant, aerobic stability, and disgestibility of bermudagrass ensiled at two moisture contents. J. Anim. Sci.,69(11):4588-4601.

VAN SOEST, P.J. 1994. Nutritional ecology of ruminant. Corvallis: O \& B Books. 476p.

VILELA, D., ALVIM, M.J. Manejo de pastagens do gênero Cynodon: introdução, caracterização e evolução do uso no Brasil. In: SIMPÓSIO SOBRE MANEJO DE PASTAGEM, 15, 1998, Piracicaba. Anais... Piracicaba:FEALQ, 1998, p.2354. 1998.

WOOLFORD, M. K. 1984. The silage fermentation. New York: Marcel Dekker. 305p.

Recebido em: 10/03/1999 Aceito em: 16/11/1999 